\title{
Idaho National Engineering and Environmental Laboratory Environmental Technologies Proof-of-Concept Final Report FY-96
}

\author{
S. L. Barrie \\ G. S. Carpenter \\ A. B. Crockett \\ W. C. Downs \\ K. J. Dooley \\ R. J. Gehrke \\ R. L. Heath \\ P. A. Lazzarotto \\ R. M. Lehman \\ P. A. Lessing \\ M. Little \\ D. T. Maiers \\ D. F. Suciu \\ T. A. Todd \\ C. E. Turick \\ J. R. Weidner \\ P. L. Wichlacz \\ P. M. Wikoff
}

Published April 1997

Idaho National Engineering Laboratory Environmental and Life Sciences Products Lockheed Martin Idaho Technologies Company Idaho Falls, Idaho 83415

Prepared for the

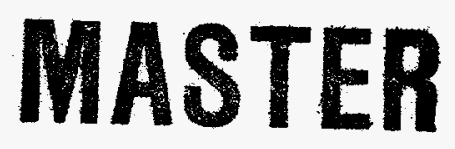

U.S. Department of Energy

Assistant Secretary for Environmental Management Under DOE Idaho Operations Office

Contract DE-AC07-94ID13223 


\section{DISCLAIMER}

This report was prepared as an account of work sponsored by an agency of the United States Government. Neither the United States Government nor any agency thereof, nor any of their employees, makes any warranty, express or implied, or assumes any legal liability or responsibility for the accuracy, completeness, or usefulness of any information, apparatus, product, or process disclosed, or represents that its use would not infringe privately owned rights. Reference herein to any specific commercial product, process, or service by trade name, trademark, manufacturer, or otherwise does not necessarily constitute or imply its endorsement, recommendation, or favoring by the United States Government or any agency thereof. The views and opinions of authors expressed herein do not necessarily state or reflect those of the United States Government or any agency thereof. 


\section{DISCLAIMER}

Portions of this document may be illegible electronic image products. Images are produced from the best available original document. 
Idaho National Engineering and Environmental Laboratory Environmental Technologies Proof-of-Concept Final Report FY-96

INELEXT-97-00412

Prepared by
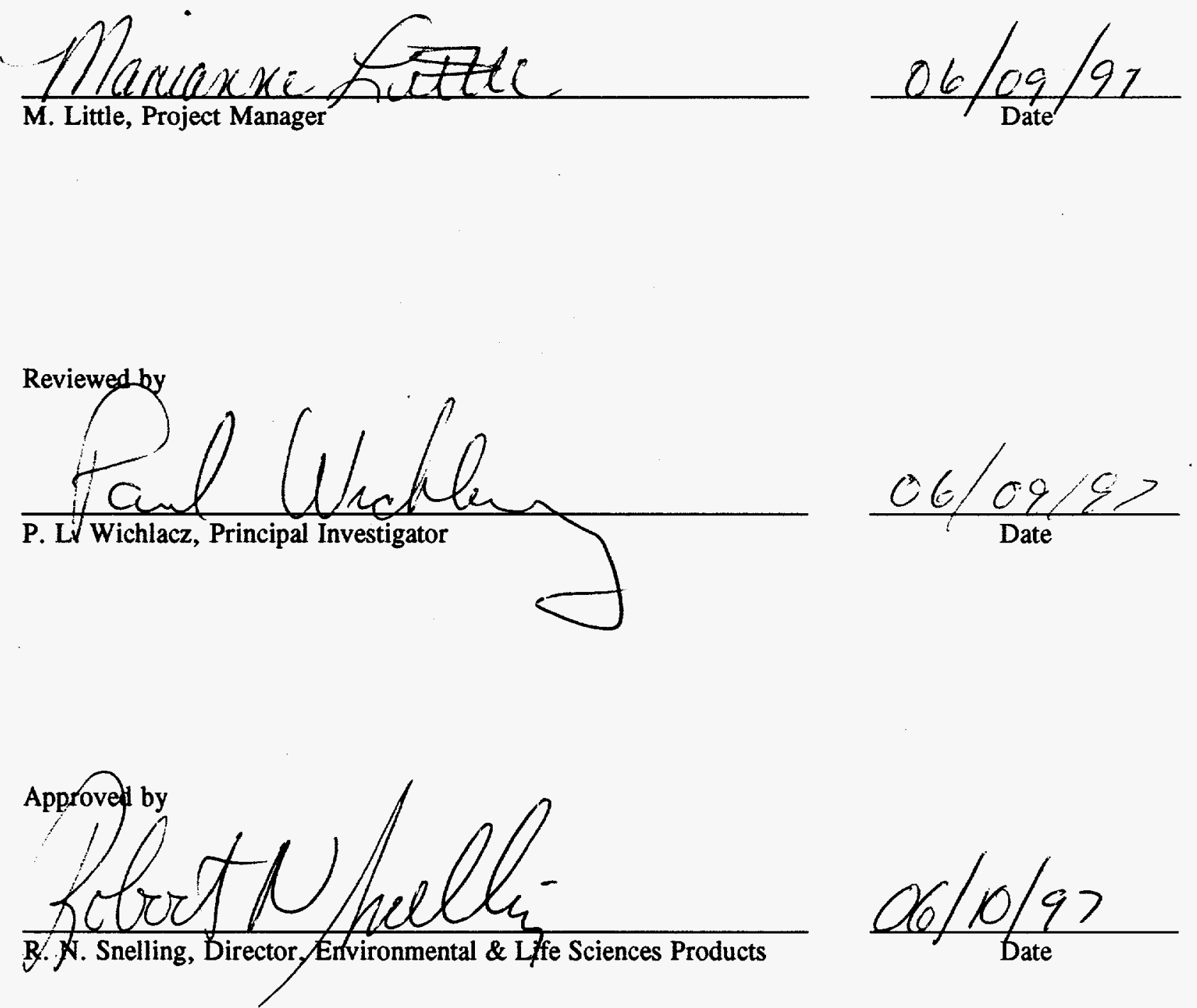


\begin{abstract}
The Idaho National Engineering and Environmental Laboratory Environmental Technologies Proof-of-Concept Project was initiated for the expedited development of new or conceptual technologies in support of groundwater fate, transport, and remediation; buried waste characterization, retrieval, and treatment; decontamination and decommissioning; mixed waste treatment; waste minimization/pollution prevention; and spent fuel handling and storage. In Fiscal Year 1996, The Idaho National Engineering and Environmental Laboratory proposed 40 development projects and the Department of Energy funded 15. The projects proved the concepts of the various technologies, and all the technologies contribute to successful environmental management.
\end{abstract}




\section{SUMMARY}

The Idaho National Engineering and Environmental Laboratory (INEEL) Environmental Technologies Proof-of-Concept Project was initiated to provide a flexible funding capability for the development of new or conceptual environmental technologies. In addition, initial startup resources were made available for new development projects approved under the auspices of the Proof-of-Concept Project. Projects were to support groundwater fate, transport, and remediation; buried waste characterization, retrieval, and treatment; decontamination and decommissioning; mixed waste treatment; waste minimization/pollution prevention; and spent fuel handling and storage.

Of the 40 projects proposed, the following 15 , which met a majority of the funding criteria (see Table 1 page 3), were funded: (1) Volume Source Efficiencies and Coincidence Corrections, (2) INEEL Stabilization Project, (3) Application of Electrochemical Oxidation and Cross-Flow Microfiltration, (4) Low Cost Vitrification Alternative, (5) Removal of Radionuclides from Test Area North (TRA) Groundwater, (6) Passive Soil Vapor Extraction, (7) Rapid Geophysical Surveyor for Unexploded Ordinance, (8) In Situ Sampling of Aqueous-Phase Contaminants by Chlorinated Solvents, (9) Evaluation of Fenton's Based Remediation for INEEL Explosive Contaminated Soil, (10) Rapid and Ecologically Relevant Assessment of Mixed Contaminants in Groundwater, (11) Gamma-Ray Spectrometry Utilization for NDE/NDA of Mixed Waste, (12) Technology Demonstration of $\mathrm{Cr}(\mathrm{VI})$ Reducing Bioreactor, (13) Box Canyon Polyurethane Research, (14) Comparison of IMS Screening with Method 8330, and (15) Natural Attenuation of Groundwater at Test Area North.

The FY-96 program was extremely successful in proving new concepts and technologies. Specific examples include:

1. The development of a methodology for modeling Germanium (Ge) detector efficiencies by Monte Carlo techniques, and for the automatic calculation of coincidence summing corrections for extended sources. These techniques can be applied to the assay of samples and in situ, gamma-ray Ge measurements. This significantly increases the accuracy in sampling ( 15 to 30 percent) and minimizes the need for extended sources for standard calibration of the detector.

2. Utilizing three solidification materials (phosphate, iron sulfate, and hydroceramics) to stabilize incineration ash and shredded cryogenic waste. All of the waste-form materials functioned successfully as waste containment materials. These solidification materials allow for a low- 
cost method, relative to thermal treatment, for stabilizing incineration ash and shredded cryogenic waste.

3. Applying electrochemical oxidation and cross-flow microfiltration for treatment of groundwater at Test Area North to destroy the trichloroethylene and remove cesium and strontium. Electrochemical oxidation removed the trichloroethylene to below the detection limit for chemical oxygen demand (low range). The removal of strontium by cross-flow microfiltration was evaluated using fluoride, phosphate, and carbonate precipitating agents. Phosphate was most effective at the low concentrations resulting in $83 \%$ removal. These lab-scale studies show the science works, scale-up should follow.

4. Stabilizing incinerator ash in a ceramic waste form using a liquid-phase sintering technology. The project demonstrated the merits of this RocTec ${ }^{\mathrm{MM}}$ technology for processing five different surrogates for hazardous and radioactive compounds as a function of waste loading (up to $80 \mathrm{vol} . \%$ ) and ash from a municipal waste incinerator. It was demonstrated that these wastes can be fabricated into sintered pellets consisting of a vitreous/crystalline form without requiring a melter. Advantages of this technology over melter technologies include: cost (no replacement of the refractories is necessary), safety (a fully contained systems is possible), and efficiency (no pouring of the melt is needed).

5. Utilizing ion exchange sorbents to remove ${ }^{90} \mathrm{Sr}$ and/or ${ }^{137} \mathrm{Cs}$ from groundwater. The groundwater treatability studies indicate that there are a number of sorbents available that effectively remove cesium and strontium from groundwater. These results will provide a basis from which more effective $\mathrm{Sr}$ and $\mathrm{Cs}$ removal systems can be developed.

6. Successful demonstration of the Passive Soil Vapor Extraction technology at the Boise airport has resulted in requests for its installation at other sites. Most recently an installation has been requested at a gasoline station in Preston, Idaho.

7. Mapping the distribution of surface and buried unexploded ordnance (UXO) using magnetic field mapping equipment. The Rapid Geophysical Surveyor (RGS), originally developed at the INEEL and licensed to Sage Earth Science, produced, at two sites, high fidelity magnetic field maps that show the distribution of ferrous and magnetic debris. These maps were produced quicker and cheaper than "hand mapping".

8. Improving the design of the in situ sampler, developed in FY-95, for sampling methane in addition to trichloroethene (TCE), generating calibration curves for methane, and improving the detection limits. A detection limit of $2 \mathrm{ppb}$-wt for TCE was obtained in the laboratory using a gas chromatograph (GC) for the sample analysis, and a detection limit of $10 \mathrm{ppb}$-wt was obtained when the samples were 
analyzed in the field. Determining the amount of methane present is indicative of the microbial population for the purpose of biodegradation.

9. Using modified Fenton's reactions for remediation of soil contaminated with explosives. A very high degree of trinitrotoluene (TNT) destruction occurred in aqueous solutions in short time frames (hours). In addition, conditions were found to bypass the trinitrobenzene (TNB) endpoint barrier in the destruction pathway-a previously unreported phenomenon. Resulting in quicker, more complete distruction of explosives in soil.

10. Rapid and Ecologically Relevant Assessment of Mixed Contaminants in Groundwater: Due to troubles obtaining approval for sample collection, this project was not able to achieve the outcome hoped for. Additional Laboratory Directed Research and Development funds have been obtained to pursue the concept further.

11. Producing a specialized data collection in CD-ROM format that contains radionuclide decay data, gamma-ray spectra, and alpha particle spectra for radionuclides of interest in characterization and assay of TRU and mixed waste materials at INEEL. This task provided the basis for the determination of the content for the first version of the new edition of the Catalogues in CD-ROM format and the approach for offering information on the Internet through the Gamma-ray Spectrometry Center Web Site at the INEEL.

12. A reactor for the biochemical reduction of toxic and soluble hexavalent chromium ( $\mathrm{Cr}[\mathrm{VI}])$ to the less soluble and benign trivalent chromium (Cr[III]). The reactor successfully demonstrated using drag-out bath effluent from a military chromium plating facility and chromium contaminated groundwater from an aquifer in northeastern Connecticut. $\mathrm{Cr}(\mathrm{VI})$ reduction in this bioreactor resulted in $\mathrm{Cr}$ (III) without the need to add other inorganic chemicals as reductants or for $\mathrm{pH}$ adjustment.

13. Injecting polyurethane in vadose zone monitoring wells to isolate instruments. Strata Tech, Friendswood, Texas, material ST-541 sealed the boreholes well and filled the packers to the volume required. When compared to bentonite and Portland cement, which are currently used to isolate intervals of boreholes, the foam grouting technology is a viable candidate for further testing. Other potential applications of the foam grouting is to seal large areas for waste isolation.

14. Quantitatively evaluating a solvent extraction/Ion Mobility Spectrometry (IMS) screening procedure for a cheaper, faster, and more accurate method of screening soils for high explosive residues. IMS was found to compare favorably to other field methodology and method 8330 for filed screening of explosives contaminated soils. In 
addition, the costs and time associated with screening by IMS is much less than that of other field techniques (for comparable data).

15. Providing a science-based indication of whether Natural Attenuation could be occurring at sites with conditions such as those found at Test Area North at the INEEL. Microbial populations typically involved in aerobic degradation of TCE (methanotrophs, propanotrophs)

abundance was estimated by the Most Probable Number technique and determined to be adequate to potentially impact TCE destruction at Test Area North. When these microbial populations were then evaluated for their ability to degrade TCE in actual Test Area North groundwater, it was determined that up to $50 \%$ of the TCE present (about $200 \mathrm{ppm}$ initially) could be aerobically degraded within a six-week incubation period. This may result in over $\$ 5 \mathrm{M}$ of savings on the remediation at this site alone. 


\section{CONTENTS}

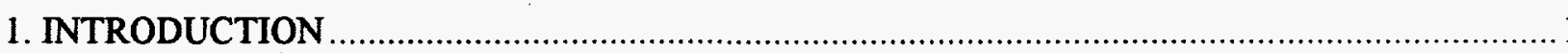

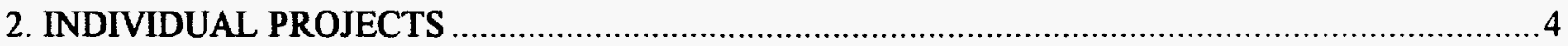

2.1. Volume Source Efficiencies and Coincidence Corrections ............................................. 4

2.2. Innovative Waste Stabilization Project ......................................................................... 4

2.3. Application of Electrochemical Oxidation and Cross-Flow Microfiltration for VOC, Strontium and Cesium Removal from Ground Water at Test Area North.......................................... 6

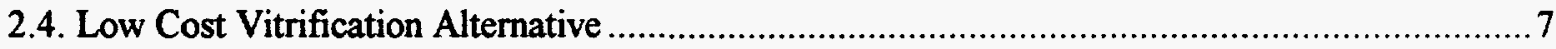

2.5. Removal of Radionuclides from Test Area North Injection Well Water................................8

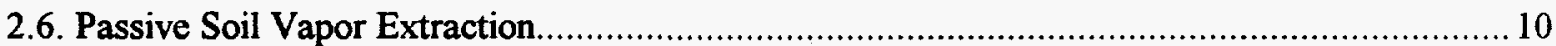

2.7. Rapid Geophysical Surveyor for Unexploded Ordnance................................................. 11

2.8. In Situ Sampling of Aqueous-Phase Contamination of Chlorinated Solvents ........................ 12

2.9. Evaluation of Fenton's Based Remediation for INEEL Explosive Contaminated Soil .............. 13

2.10. Gamma-Ray Spectrometry Utilization of NDE/NDA of Mixed Waste .............................. 14

2.11. Rapid and Ecologically-Relevant Risk Assessment of Mixed Contaminants in Groundwater... 15

2.12. Technology Demonstration of $\mathrm{Cr}$ (VI) Reducing Bioreactor ....................................... 18

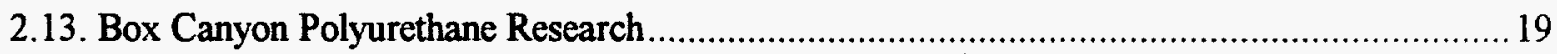

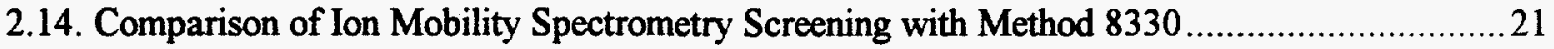

2.15. Natural Attenuation of Groundwater at Test Area North .............................................23

3. FUNDING

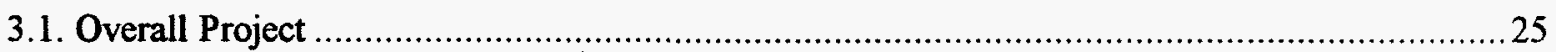

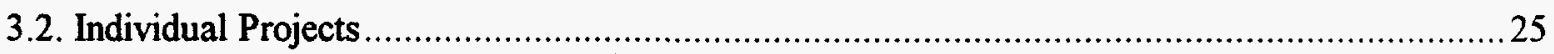

4. RESULTS 


\section{FIGURES}

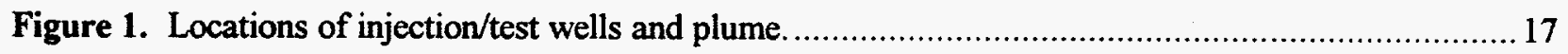

\section{TABLES}

Table 1. Criteria for funding selection.

3 


\section{Idaho National Engineering and Environmental Laboratory Environmental Technologies Proof-of-Concept Final Report FY-95}

\section{INTRODUCTION}

An innovative approach was undertaken in FY-94 and repeated in FY-95 and FY-96 to help solve funding problems that occasionally occur for environmental technologies funded under the Department of Energy (DOE) Office of Technology Development (EM-50) at the Idaho National Engineering and Environmental Laboratory (INEEL. Because of delays in funding, promising opportunities relative to compliance agreements, private sector partnering, and university involvement have been lost. The Environmental Technologies Proof-of-Concept Project was initiated to overcome delays in startup for projects by making a fund source available for expeditious project execution and flexible management. (Note: This was not a management reserve fund.)

Fifteen projects were funded in FY-96 (Technical Task Plan ID143501 and ID111701). The 15 proof-of-concept projects were initiated and funded at the discretion of an internal project selection team comprising the principal investigator, project manager, Office of Waste Technology Development product managers, and appropriate DOE program managers, with the DOE Idaho Operations Office (DOE-ID) technical program officer giving concurrence. Projects were funded to the extent necessary to complete the scope within the fiscal year or enter the normal fiscal-year-plus-one planning, budget, and execution cycle.

Projects had to meet DOE Environmental Management (EM) needs and demonstrate potential fiscal leverage and return on investment. Projects also had to meet INEEL needs including, but not limited to:

- Groundwater fate, transport, remediation

- Buried waste characterization, retrieval, treatment

- Decontamination and decommissioning

- $\quad$ Mixed waste treatment

- Waste minimization/pollution prevention

- Spent fuel handling, storage.

Product managers from the Office of Waste Technology Development issued the call for proposals. Forty proposals were received and reviewed under the product areas of:

- Pollution prevention

- Environmental restoration/waste management

- Biotechnology 
- Robotics

- Decontamination and decommissioning

- $\quad$ Mixed waste

- Supercritical water oxidation

- $\quad$ Buried waste

- Geosciences.

Listed in Table 1 are the criteria for choosing projects. The preliminary selection was based on the "Go/no-go" criteria. Twenty-six of the 40 proposals met these criteria. Further evaluation was based on the "Other considerations" criteria. Of the 26 proposals that met the preliminary criteria, 15 met the majority of considerations criteria. Below is a list of the those 15 proposals, which were funded in FY-96 as proof-of-concept projects, and their principal investigators:

- Volume Source Efficiencies and Coincidence Corrections - R. J. Gehrke

- Innovative Waste Stabilization Project - J. R. Weidner

- Application of Electrochemical Oxidation and Cross-Flow Microfiltration for VOC, Strontium, and Cesium Removal from Groundwater at Test Area North - P. M. Wikoff and D. F. Suciu

- Low Cost Vitrification Alternative - P. A. Lessing

- Removal of Radionuclides from Test Area North Injection Well Water - T. A. Todd

- Passive Soil Vapor Extraction - W. C. Downs

- Rapid Geophysical Survey of Unexploded Ordinance - G. Carpenter

- In Situ Sampling of Aqueous-Phase Contamination of Chlorinated Solvents - S. L. Barrie and K. J. Dooley

- Evaluation of Fenton's Based Remediation for INEEL Explosive Contaminated Soil - A. B. Crockett

- Gamma-Ray Spectrometry Utilization of NDE/NDA of Mixed Waste - R. L. Heath

- Rapid and Ecologically Relevant Assessment of Mixed Contaminants in Groundwater - R. M. Lehman

- Technology Demonstration of Cr(VI) Reducing Bioreactor - C. E. Turick 
- Box Canyon Polyurethane Research - S. L. Barrie and K. J. Dooley

- Comparison of Ion Mobility Spectrometry (IMS) Screening with Method 8330 - A. B. Crockett

- Natural Attenuation of Groundwater at Test Area North - D. T. Maiers

Table 1. Criteria for funding selection.

\begin{tabular}{ll}
\hline \multicolumn{1}{c}{ Go/no-go } & \multicolumn{1}{c}{ Other considerations } \\
\hline $\begin{array}{l}\text { Proof of concept } \\
\text { Serves environmental restoration/waste } \\
\text { management need (EM) }\end{array}$ & Quick win \\
Committed within fiscal year & Regional benefit \\
Product orientation (no paper studies) & University collaboration \\
Secondary waste streams consideration & Follow-on technology transfer program \\
Facilities/utilities/logistics & Potential/sponsorship \\
Availability & $<\$ 50 \mathrm{~K}$ (preferred) \\
Regulatory concerns (DOE/Idaho/other state) & Other fund sources exhausted \\
Public acceptance & \\
Environmental abuse (air/soil/groundwater)
\end{tabular}




\title{
2. INDIVIDUAL PROJECTS
}

\subsection{Volume Source Efficiencies and Coincidence Corrections}

\author{
Principal Investigator: R. J. Gehrke
}

The purpose of this project was to develop the methodology for modeling Germanium (Ge) detector efficiencies by Monte Carlo techniques and for the automatic calculation of coincidence summing corrections for extended sources. When low-activity volume samples are counted in geometry's close to the detector, the peak efficiency must be known to measure $\gamma$-ray emission rates and the total efficiency known to correct for any coincidence summing. This project focused on a disk source $65-\mathrm{mm}$ in diameter and 3-mm thick counted on the window of an n-type Ge detector with a detection sensitivity over the energy range from $\sim 10$ to $>2000 \mathrm{keV}$.

A Monte Carlo electron and photon transport code (CYLTRAN) was used to compute peak and total efficiencies for various photon energies at 30 points throughout the sample disk volume. The geometry modeled for these calculations included the various components of the detector and source along with the surrounding shielding. These data were used to compute the average peak and total efficiencies as a function of the $\gamma$-ray energy from 30 to $2000 \mathrm{keV}$. These data were also used to determine the effective total efficiencies that apply to the coincidence summing corrections. The associated coincidence summing corrections were computed at the various positions in the sample volume and the average for the whole source. The influence of the soil and the detector shielding, which was close to the detector, on the total efficiencies and the coincidence summing corrections was investigated. The results of this study demonstrated that the effective detector efficiencies for the disk shaped sample could be obtained from averaging a family of plane disk or individual point efficiencies through the sample. Correction for coincidence summing for a disk shaped soil sample spiked with ${ }^{152} \mathrm{Eu}$ resulted in the emission rates of the stronger $y$ rays being in agreement to $\pm 3 \%$ from 122 to $1112 \mathrm{keV}$. The results of this study were reported at the International Committee on Radionuclide Metrology Working Group Symposium September 1996 at St. Petersburg, Russia.

The experience gained from successfully using Monte Carlo modeling on a disk source will be extended in FY-97 to in situ Ge $\gamma$-ray spectrometry. Canberra Industries has shown interest in collaborating with us in the extended study. Hopefully, these techniques will become acceptable in Environmental Protection Agency (EPA) methods used in the radioanalytical laboratory and at environmental cleanup sites to provide consistent and validated activity concentrations and to reduce the amount of environmental media being disposed of as radioactive material.

\subsection{Innovative Waste Stabilization Project}

\author{
Principal Investigator: J. R. Weidner
}

The purpose of this project was to demonstrate three waste-form materials for stabilizing waste. These include a phosphatic material developed at the Argonne National Laboratory East, which functions by encapsulating and reacting with the hazardous components in the waste, a ferrous sulfate, and a hydroceramic. The phosphatic form material was tested to determine if it is a potential material to contain and immobilize shredded waste, and also to stabilize power-plant fly ash. All three waste forms were tested to determine if they are potential materials to contain and stabilize power-plant fly ash. The results of the 
tests indicate that all of the innovative waste-form materials functioned successfully to immobilize the hazardous components in fly ash.

The project was organized as two tasks: (1) Determining if the phosphate waste form developed at the Argonne National Laboratory East can be used to stabilize debris resulting from the FY-92 cryofracture, and (2) Comparing the properties of three waste-form materials when used to stabilize power-plant fly ash.

Phosphate materials were chosen because minerals such as monazite are the host for radioactive elements and are insoluble in ground water. Thus, it is possible to form insoluble phosphate compounds of the contaminants thereby chemically fixing them. In addition, the contaminants are encapsulated in a mechanically tough phosphatic matrix to provide a durable containment system.

The iron sulfate based materials are an out-growth of the successful waste encapsulation material produced by mixing the agricultural reagents slaked lime $\left(\mathrm{Ca}(\mathrm{OH})_{2}\right)$ and ferrous sulfate to produce iron oxyhydroxide compounds and gypsum $\left(\mathrm{CSO}_{4} 2 \mathrm{H}_{2} \mathrm{O}\right)$. In the present proof-of-concept study, fly ash was substituted for the slacked lime to determine if iron oxyhydroxide would be produced and if it would immobilize the hazardous metals (as defined by the EPA).

Hydrothermal treatment of waste involves mixing the waste in proper proportions with water and Blue Circle slag-type cement and heating the mixture in a sealed container under pressure in order to produce a very hard and insoluble hydroceramic waste form, i.e., a ceramic waste form produce under hydrothermal conditions.

Task 1

The cryofracture debris from the FY-92 demonstration was shipped to Argonne East. The Argonne developed phosphate waste-form material was blended with the shredded waste and the contaminant-spiked fly ash (see below) and put in 1.5 gallon and four gallon containers. The unsupported compressive strength of the solidified material was measured on the full-sized waste-form monoliths so that the effect of the shredded waste would be included in the compressive strength results. Measured, unsupported, compressive strength was 1300 psi with standard deviation (SD) of $100 \mathrm{psi}$, indicating a mechanically excellent waste form.

Task 2

One representative sample of American Society for Testing and Materials (ASTM) type F powerplant fly ash was spiked with the eight hazardous EPA metals so that their total concentration was 1 wt\%. Each of the test waste-form materials were used to treat a split of the spiked ash. Waste loadings were about $67 \mathrm{wt} \%$ or more. The phosphate waste forms were prepared at Argonne National Laboratory East. The iron sulfate waste forms were prepared at INEEL's Idaho Research Center. The hydroceramic waste forms were prepared at INEEL's Idaho Chemical Processing Plant (ICPP).

Characterization of the waste forms was carried out using compressive strength tests, toxicity characterization leaching procedure (TCLP) leach tests, scanning electron microscopy (with $x$-ray fluorescence analysis) to determine microstructure and phase chemical composition, and X-ray powder diffraction to determine the crystalline species.

The unsupported compressive strength of all waste forms exceeded the Nuclear Regulatory Commission (NRC) 50 psi minimum. The hydroceramic had the highest strength, 35,000 psi (SD 23,000), 
followed by the phosphate with 5360 psi (SD 800 ) and iron sulfate based materials, the least with 100 psi (SD 50)

The TCLP standard leach test indicated that the iron sulfate and phosphate waste forms reduced the leachability of silver, chrome, mercury, lead, and barium to below regulatory limits. The iron sulfate waste materials also reduced the leaching of arsenic and selenium, but not cadmium, to levels below regulatory limits. The phosphate material also reduced the leaching of cadmium, but not arsenic and selenium, to levels below regulatory limits. The TCLP standard leach test indicated that the hydroceramic decreased the leachability of chrome, silver, mercury, cadmium, arsenic, selenium, lead, and barium, to levels below regulatory limits. However, the hydroceramic probably lost mercury by volatilization during the pretreatment preparation.

All of the waste-form materials tested in this proof-of-concept study indicate great potential as waste containment materials. The phosphate and hydroceramic materials are ready for pilot-scale and field-scale testing. The iron sulfate materials may also be pilot scale and field scale tested. However, it is recommended that the next step in the development of these materials be a thermochemical analysis of the chemical system ferrous sulfate, slaked lime, with the ASTM fly ash compositions to determine the optimum blending ratios to produce additional contaminant immobilizing phases as ettringite and others, and also to produce a composition which has higher unsupported compressive strength.

This project will be followed up with the Mixed Waste Focus Area Quick Win project.

\title{
2.3. Application of Electrochemical Oxidation and Cross-Flow Microfiltration for VOC, Strontium, and Cesium Removal from Ground Water at Test Area North
}

\author{
Principal Investigators: P. M. Wikoff and D. F. Suciu
}

The objective of this project was to determine if Electrochemical Oxidation and Cross-Flow Microfiltration could successfully treat groundwater at Test Area North to destroy the trichloroethylene and remove cesium and strontium. The Ground Water Treatment Facility (GWTF) at Test Area North is designed to treat contaminated water from the INEEL's Test Area North Injection Well Technical Support Facility, wells TAN-25 and TAN-26, and other monitoring wells at Test Area North.

The Neutral Precipitation Cross-Flow Microfiltration process-an industrial, low-cost wastewater treatment unit process-minimizes the chemical cost and sludge production for the treatment of these wastewaters for heavy metal removal. At the same, the unit process can be easily operated, and its procurement and installation is economical. Environmental Research and Development (ERAD) has currently applied for a patent for this unit process.

A laboratory bench-scale unit was constructed and operated to demonstrate the technology concept in a Phase Small Business Innovative Research (SBIR). During the Phase II SBIR program a 10-gpm Pilot Demonstration Unit was designed and operated on an actual heavy metal containing industrial wastewater at the Tobyhanna Army Depot Metal Pretreatment Plant. ERAD currently has the design parameters for units up to $250 \mathrm{gpm}$. 
Process evaluation showed the reaction kinetics of the Neutral Metal Precipitation Process to be very rapid in contrast to conventional treatment processes. The rapid reaction kinetics means a wastewater treatment unit does not require the large reaction tanks associated with conventional wastewater treatment process.

A laboratory electrochemical treatment unit and a laboratory Cross-Flow Microfiltration Unit was used to demonstrate the coupled units capability of removing the organics such as trichlorethylene and the inorganics such as strontium and lead from a simulated waster similar to that seen at the Ground Water Treatment Facility. The evaluation included a determination of the appropriate complexing agents to precipitate the strontium and lead and the conditions required for the electrochemical treatment unit to oxidize the organics. In addition, appropriate removal methods for the cesium was identified (i.e., scrubbing with the Cross-Flow Microfiltration System or resin removal.)

Electrochemical Oxidation removed the trichloroethylene to below the detection limit for chemical oxygen demand (Low Range) within 15 minutes of operation with a salt concentration of $2 \%$. The removal of strontium by Cross-Flow Microfiltration using fluoride, phosphate, or carbonate was evaluated. Phosphate was most effective at the low concentrations resulting in $83 \%$ removal. Carbonate resulted in $76 \%$ removal at the low concentrations. However, at $100 \mathrm{mg} / \mathrm{L}$ carbonate, $97 \%$ of the strontium was removed. The final strontium concentration in the water was $0.05 \mathrm{~g} / \mathrm{L}$. Though tests were not run with $\mathrm{Ca}$ and $\mathrm{Mg}$, past tests @ $100 \mathrm{ppm}$ had no impact on the process. Additional $\mathrm{Ca}$ and $\mathrm{Mg}$ is not expected to effect the process.

It is felt that these processes coupled to the existing Ground Water Treatment Facility can allow the treatment plant to operate in the continuous mode as designed rather in the batch mode it is currently operating in. Pretreatment with the Electrochemical Oxidation Cross-Flow Microfiltration process could significantly reduce the loading to the Test Area North Ground Water Treatment Facility. This will reduce the chemical operating costs by reducing the amount of ion exchange resins which must be disposed of, and by reducing the carbon use required in the air stripper to remove the VOC's from the air.

A detailed report of this work is available: The Application of Electrochemical Oxidation and CrossFlow Microfiltration for VOC, Strontium, and Cesium Removal from Groundwater at Test Area North, Environmental Research and Development (ERAD) Report, ERAD-01-96.

\subsection{Low Cost Vitrification Alternative}

\section{Principal Investigator: P. A. Lessing, Ph.D.}

The purpose of this project was to demonstrate that incinerator ash could be stabilized in a ceramic waste form using liquid-phase sintering technology known a RocTec ${ }^{\mathrm{TM}}$ processing. The project objective included fabrication of RocTec ${ }^{\mathrm{TM}}$ ceramic waste forms with high loading of ash and surrogate radioactive materials.

The project demonstrated the merits of RocTec ${ }^{\mathrm{TM}}$ technology for processing five different surrogates for hazardous and radioactive compounds as a function of waste loading (up to 80 vol.\%) and ash from a municipal waste incinerator. It was demonstrated that these wastes can be fabricated into sintered pellets consisting of a vitreous/crystalline form without requiring a melter. This eliminates several problems common to all melter systems, namely: 
- No assay of the waste to control viscosity is required

- No replacement of refractory is necessary

- No pouring of the melt is needed

- There is avoidance of carryover dust and radionuclides through aqueous processing techniques.

The reducing atmosphere used for the RocTec ${ }^{\mathrm{TM}}$ process produces crystalline ceramic phases that appear to be different than those phases formed in an oxidizing atmosphere. As a consequence, the process produces a waste form with excellent attributes that include the following properties:

- High Density (>94\% of theoretical)

- High waste loading (up to 90 vol.\%)

- Good chemical stability (high leach resistance)

- Crystalline phases that possess high strength.

The green forming during the RocTec ${ }^{\mathrm{TM}}$ process is simple and amenable to a variety of processing techniques such as dry pressing, wet extrusion, and dry tamping. Also, the firing step takes place at moderate temperatures utilizing simple industrial furnaces. Therefore, the process is amenable to scale-up.

To follow up on this project, a proposal was submitted to DOE as a joint project by LMITCO and Nuclear Metals, Inc. (TRIOX being a subcontractor). The purpose of this proposal is to scale-up the process at the Nuclear Metals Facility in Barnswell, South Carolina, and demonstrate a "quick win" stabilization of actual ashes (fly ash or fly ash and bottom ash) generated by the combustion of mixed waste at INEEL's Waste Experimental Reduction Facility (WERF). If successful, the process will also apply to sludges or contaminated soils, and ash stabilization at other DOE rad-waste incinerators, such as the Oak Ridge TSCA, and Savannah River CIF.

\title{
2.5. Removal of Radionuclides from Test Area North Injection Well Water
}

\author{
Principal Investigator: T. A. Todd
}

The objective of this proof-of-concept project was to test novel ion-exchange sorbents, many recently developed through the DOE EM Science and Technology Program, on actual Ground Water Treatment Facility contaminated groundwater. Ion exchange sorbents were tested for removal of ${ }^{90} \mathrm{Sr}$ and $/$ or ${ }^{137} \mathrm{Cs}$, with the intent of comparing the sorbents removal efficiencies and breakthrough capacities.

The Ground Water Treatment Facility was constructed in 1994 to initiate a CERCLA interim remedial action of the TSF-05 injection well at the INEEL's Test Area North. Higher than expected levels of ${ }^{137} \mathrm{Cs}$ and the inability of the Ground Water Treatment Facility to effectively remove ${ }^{90} \mathrm{Sr}$ from the groundwater prevented operation of the Ground Water Treatment Facility at design capacity. In August 1995 the US DOE, US EPA, and the Idaho Department of Health and Welfare jointly signed a Record of 
Decision for the cleanup of contaminated groundwater associated with the TSF-05 injection well and surrounding contaminated plume, referred to as Operable Unit (OU) 1-071B.

Two experimental setups were installed in the Ground Water Treatment Facility, each containing two glass ion-exchange columns $2.5-\mathrm{cm}$ diameter by $30-\mathrm{cm}$ high, connected in series. Each column was filled with sorbent to a height of $25.4 \mathrm{~cm}$. Each setup contained a cesium sorbent in the first column and a strontium sorbent in the second column. Setup A contained Pellx-137, a cesium selective zeolite in the first column, and Ionac C-250, a commercially-available sorbent in the second column. Ionac C-250 represented the current Ground Water Treatment Facility system and was used as a control or baseline. Setup B contained Cs-treat, a commercially available potassium cobalt hexacyanoferrate in the first column, and a commercial sodium titanate produced by Allied Signal in the second column. Additionally, a single column containing Ionsiv-911 or crystalline silicotitanate (CST) was tested. The CST is selective for both cesium and strontium in near-neutral $\mathrm{pH}$ solutions.

As part of Ground Water Treatment Facility operations, contaminated groundwater was pumped into a large receiving vessel and recirculated through an air stripper for volatile organic removal, and filtered. Slip streams were taken of the recirculating water after filtration and pumped through the ion-exchange columns at a flowrate of $20 \mathrm{~mL} / \mathrm{min}$., which equates to 10-bed volumes per hour. The effluent from each setup was returned to the Ground Water Treatment Facility system. The Ground Water Treatment Facility was operated in a recirculating mode for approximately 2 to 4 days per batch of injection well water, then the water was pumped back into the well and new water pumped into the Ground Water Treatment Facility holding cell. The ion-exchange setups were operated in a continuous manner around the clock when the Ground Water Treatment Facility was recirculating water. Samples of column effluents (after the first [Cs] column and after the second [Sr] column) were taken periodically and transported to the Idaho Chemical Processing Plant for chemical and radiological analyses. One liter samples were counted for gamma emission $\left({ }^{137} \mathrm{CS}\right)$ and then $500 \mathrm{~mL}$ of the sample were analyzed for ${ }^{90} \mathrm{Sr}$. There is no detectable stable cesium in the water, however, there is a significant amount of stable strontium. Total strontium analysis was performed on the feed samples and the ratio of stable strontium to ${ }^{90} \mathrm{Sr}$ was used to determine total strontium in eluent samples. Other elemental analyses $(\mathrm{Mg}, \mathrm{Ca}$, etc.) were performed using ICP-MS.

At the time of testing, the TSF-05 injection well pump was out of service, and water from TSF-25 was being treated at the Ground Water Treatment Facility. The water from TSF-25 curtains lower concentrations of ${ }^{137} \mathrm{Cs}$ and ${ }^{90} \mathrm{Sr}$ than TSF-05. Feed concentrations in the TSF-25 water ranged from about 400 to $700 \mathrm{pCi} / \mathrm{L}$ for ${ }^{137} \mathrm{Cs}$ and 200 to $300 \mathrm{pCi} /$ for ${ }^{90} \mathrm{Sr}$. The maximum contaminant level $(\mathrm{MCL})$ for the groundwater is $119 \mathrm{pCi} / \mathrm{L}$ for ${ }^{137} \mathrm{Cs}$ and $8 \mathrm{pCi} / \mathrm{L}$ for ${ }^{90} \mathrm{Sr}$.

Results from Setup A testing indicate that no cesium was detectable in the effluent $(<4 \mathrm{pCi} / \mathrm{L})$ from the column containing Pellx-137 for the duration of the test which processed $174 \mathrm{~L}$ of water (1450-bed volumes). The capacity of the Pellx-137 sorbent was not determined, since breakthrough was not observed. The Ionac C-250 column appeared to reach initial Cs breakthrough at 1100 bed volumes and was at approximately $15 \%$ breakthrough at the conclusion of the test (1450-bed volumes). Prior to breakthrough, the Ionac $\mathrm{C}-250$ column was very effective at removing ${ }^{90} \mathrm{Sr}$ to $<6 \mathrm{pCi} / \mathrm{L}$. An interesting phenomenon was observed in the Setup A testing. Total strontium concentrations in the effluent from the Pellx-137 column were higher than initial feed concentrations, while ${ }^{90} \mathrm{Sr}$ activities were lower in the effluent stream. It appears that the Pellx-137 sorbent contains small amounts of stable strontium which was leached from the sorbent (increasing the total strontium concentration) and some exchange of radiostrontium for stable strontium in the Pellx-137 sorbent occurred, (decreasing the activity of ${ }^{90} \mathrm{Sr}$ in the effluent). 
Results from Setup B testing indicate that no cesium was detectable in the effluent $(<14 \mathrm{pCi} / \mathrm{L})$ from the column containing Cs-treat (potassium cobalt hexacyanoferrate) for the duration of the test which processed $253 \mathrm{~L}$ of water (2100-bed volumes). The capacity of the Cs-treat sorbent was not determined, since breakthrough was not observed. The sodium titanate column was effective at removing ${ }^{90} \mathrm{Sr}$ to levels between 17 and $29 \mathrm{pCi} / \mathrm{L}$, which is above the $\mathrm{MCL}$ of $8 \mathrm{pCi} / \mathrm{L}$. Breakthrough of strontium in the sodium titanate column was also not observed.

Approximately $142 \mathrm{~L}$ of water (1180-bed volumes) were treated with the Ionsiv-911 column, including nearly $40 \mathrm{~L}$ of TSF- 05 water with a ${ }^{137} \mathrm{Cs}$ concentration of $1117 \mathrm{pCi} / \mathrm{L}$. The cesium activity in the effluent from the column contained $<13 \mathrm{pCi} / \mathrm{L}$. Strontium analysis for the TSF- 05 feed and effluent streams is pending.

The results of the groundwater treatability studies indicate that there are a number of sorbents available that effectively remove cesium and strontium from groundwater. Except for the Ionac C-250 sorbent capacities could not be determined from this study. This information would be necessary to generate life-cycle treatment costs. Based on these results and previous work with Test Area North groundwater, it is expected that cesium sorbents will have high capacities due to lack of interference from other ions in the water. Capacity of strontium sorbents is usually the cost driver in decontaminating groundwater for two reasons: significantly higher mass of stable strontium in groundwater (relative to radiostrontium) and competition from over divalent cations, primarily $\mathrm{Mg}$ and $\mathrm{Ca}$. Both of these factors result in lower capacities of strontium sorbents relative to highly selective cesium sorbents The results of this study can be used as a basis for future investigation of strontium and cesium removal technologies for the treatment of contaminated groundwater. If possible, future testing should be conducted with TSF-05 water to provide more definitive sorbent capacity information.

\subsection{Passive Soil Vapor Extraction}

\section{Principal Investigator: W. C. Downs}

The objective of this project was to demonstrate the Passive Venting Technology at several sites. Successful demonstrations would result in the potential to enter into cooperative agreements between LMITCO and private industry to adapt the DOE-developed technology for commercial application.

Cooperative efforts were pursued with DuPont/CONOCO, UNOCAL, and the State of Idaho Department of Environmental Quality (DEQ) as follows:

\section{Dupont/CONOCO}

Negotiations were entered into with DuPont and DuPont/CONOCO to apply the Passive Venting Technology to underground storage or oil refinery sites. Several sites were considered with a final selection of a DuPont/CONOCO oil refinery site in Ponca City, Oklahoma. However, during the processing of an agreement, a management change occurred that resulted in a hold being placed on environmental remediation activities for that refinery site. As a result, negotiations with DuPont/CONOCO were terminated.

\section{UNOCAL}

Discussions were held with UNOCAL, an oil company in California interested in applying passive injection to contaminated underground storage tank areas. The passive injection technology would be used 
to stimulate microbial growth (bioventing) in the contaminated areas. The project staff of both LMITCO and UNOCAL agreed in the spring of 1996 to install the passive injection at a UNOCAL site in Nevada. LMITCO staff initiated processing of a CRADA with UNOCAL. However, during the processing of the agreement, the LMITCO legal department could not agree with the UNOCAL indemnification terminology and negotiations were terminated.

$\underline{\mathrm{DEQ}}$

The Passive Venting Technology was installed in the fall of 1996 at a gas station at the Boise airport in cooperation with the State of Idaho Department of Environmental Quality (DEQ). The purpose of the test is to determine the feasibility of a low-cost mechanism for remediating contaminated underground storage tanks. A successful demonstration will result in the DEQ recommending the technology as an acceptable method to address underground storage tank contamination in the State of Idaho.

A passive venting valve was installed at the Boise Airport, and will be monitored until spring of 1997. DEQ staff are maintaining the site, downloading data, and transmitting it to Dr. Downs for evaluation. Current data assessments indicate an extremely successful demonstration-the technology is venting contaminants at the highest rate experienced to date.

As a result of this testing the Passive Venting Technology has been submitted for an R\&D 100 Award, and the State of Idaho has requested a valve be installed at a gas station at Preston, Idaho.

\subsection{Rapid Geophysical Surveyor for Unexploded Ordnance}

\section{Principal Investigators: G. Carpenter}

The purpose of this project was to demonstrate the utility of Sage Earth Science's (SES) Rapid Geophysical Surveyor (RGS) technology for unexploded ordnance (UXO) site characterization. SES mapped portions of two UXO sites at the INEEL with its proprietary technology. The RGS is a low cost, high fidelity, magnetic field mapping system originally developed at the INEEL and licensed to SES. The project accurately reflects the high utility and usefulness of this unique technology.

The productivity of the RGS system is a function of the profile spacing and site conditions. The system is adjustable to accommodate variable profile or grid spacing. At the proposed profile spacing (40 inch), 10 acres can be surveyed each day. At the second profile spacing ( 20 inch), 5 acres can be surveyed each day. If for example, the objective is a burial pit or trench with little surface clutter, perhaps 2 meter spacing would be appropriate. At that spacing, 15 to 20 acres per day can be surveyed. On the other hand, if half meter spacing is called for, 3 to 5 acres per day can be achieved.

As those familiar with magnetic sensing systems are aware, detection ranges are a function of the distance to the target, the target mass, magnetic properties of the target, and the system sensitivity. The only parameters under the control of those performing the survey are the system sensitivity and to a degree, the distance to the target. The RGS addresses these issues by minimizing the distance to the target by collecting closely spaced data. The overall system sensitivity is a function of the sensor sensitivity and data spacing. Most commercially available sensors of reasonable quality easily achieve sensitivities adequate to get down in the noise levels produced by clutter, geology, and delivery systems. 
Two sites were selected for this demonstration. The first site is known as the Large Detonation Area. At this site, large explosions were initiated to test for sympathetic detonations of closely stored materials. Two and one half acres including one crater area were mapped.

The second 1-1/2 acre site is called the Fuse Burn Area. This site was selected because low mounds of unknown origin are present. These mounds were thought to possibly be burial sites for UXO waste. A map of the magnetic field would be useful in determining the nature of these features and documenting the investigation.

The developed maps show color amplitude plots of the magnetic gradient data for these sites. Included on the maps are the locations of relevant cultural features such as building and known utilities, as well as interpreted items. Coordinate annotation corresponds to a local coordinate system setup for the purpose of these surveys. Positive magnetic gradient areas are marked by red and purple colors. Negative magnetic gradient areas are marked by green and blue colors.

The coordinate system for these maps are tied to flagging placed at the site. All measurements from the maps can be referenced to these markers in the field.

At each of the two sites, high fidelity magnetic field maps have been produced that show the distribution of ferrous and magnetic debris at the site. It is the map representation revealing the spatial relationships of site features that adds meaning and value over conventional UXO sweep techniques. These maps will serve as a tool to understand the nature and scope of contamination and as a guide for activities that will be required to control or remediate these sites.

This project demonstrates the appropriate use of remote sensing mapping technologies in UXO applications. Current mapping technologies are short of replacing conventional sweep techniques currently used during remediation of sites containing random, shallow, scattered ordnance. Most mapping systems suffer from their ability to cope with even moderate topography and vegetation. These short comings severely limit their usefulness for replacing conventional sweep techniques in many applications. Mapping systems such as the RGS however are appropriately used to characterize sites as to the nature and scope of contamination and when the spatial distribution of ordnance has special meaning (e.g., pits, trenches, burn and test sites). Mapping systems can be used to learn the volume of material and its distribution on the site. It is this kind of information that allows decision makers to plan, schedule, budget and choose appropriate remediation strategies.

This project illustrated that the RGS can perform the mapping role much more cost effectively and in a significantly wider range of topography and vegetation than competing systems.

A detailed report of this work is available: Rapid Geophysical Surveyor, Unexploded Ordnance Mapping Demonstration, Sage Earth Science, 1996.

\title{
2.8. In Situ Sampling of Aqueous-Phase Contamination of Chlorinated Solvents
}

\author{
Principal Investigators: S. L. Barrie and K. J. Dooley
}

The objective of this project was to improve the design of the sampler, generate calibration curves for methane, and improve the detection limits for trichloroethene (TCE) for in situ sampling semi-permeable 
membrane technology. The design changes made included improving the seals in the sampler, making it more rugged, and producing a smaller sampler that would fit into smaller groundwater wells. The pumping system used for collecting the vapor samples from the in situ sampler was also to be redesigned to allow the collection of two samples simultaneously. Included was a field test of the new equipment.

TRI (a subsidiary of TSI Incorporated) worked to develop the calibration curves for methane, improve the detection limits for TCE, and improve the design of the vapor collection apparatus. LMITCO employees worked on the tasks of improving the seals in the sampler, making it more rugged, and producing a smaller sampler.

New designs to improve the seals were developed simultaneously with designs to change the size of the sampler to under 1 inch. New samplers with a diameter of less than 1 inch were built at the INEEL and the seals were proven effective at $200 \mathrm{ft}$ of water. These samplers were sent to the laboratory at TRI for the development of the methane calibration curves and to improve the detection limits for TCE. TRI obtained a pressure vessel in which they placed known aqueous concentrations of TCE. They then tested the samplers under pressure and at controlled temperatures to develop calibration curves and methods of obtaining the best samples. During this same time, TRI developed (in their lab) a device that allowed the collection of two samples simultaneously.

A detection limit of $2 \mathrm{ppb}$-wt for TCE was obtained in the laboratory using gas chromatograph (GC) for the sample analysis. A detection limit of $10 \mathrm{ppb}$-wt was obtained when the samples were analyzed in the field. The field instrument used was the RCL monitor and its lower detection limit was slightly higher than the GC used in the lab. This was insignificant though because the concentrations of TCE in the wells that were sampled ranged from approximately 100 to $250 \mathrm{ppb}$-wt TCE. Results obtained from the ISSs were very comparable to historical sampling results from conventional sampling methods.

Due to the chemistry of methane, producing known standards in aqueous solutions were much more difficult. After producing known standards of methane in the laboratory, calibration curves were developed. A lower detection of $50 \mathrm{ppb}$-wt was obtained in the laboratory. Project personnel believe that with additional work in the future, a detection limit of $10 \mathrm{ppb}-\mathrm{wt}$ is achievable.

The process for obtaining a patent for this technology was initiated during FY-96 and is still currently ongoing. There are three inventors of this technology: Scott Barrie of LMITCO, Kirk Dooley of LMITCO, and William Buttner of TSI Incorporated.

\title{
2.9. Evaluation of Fenton's Based Remediation for INEEL Explosive Contaminated Soil
}

\author{
Principal Investigator: A. B. Crockett
}

The objective of this project was to analyze parent explosive compounds. Parent explosive compounds were to be analyzed by gas chromatography. The degree of destruction, preferred stoichiometry, and bulk cost data were to be determined. Specific intermediate breakdown products of concern were also to be monitored due to their high toxicity and/or groundwater mobility. This work was done in conjunction with Washington state University.

Most results to date have shown that TNT and related explosives are oxidized rather easily by hydroxyl radicals through advanced oxidation processes such as Fenton's reagent. However, the primary 
oxidation product, formed through the oxidation of the methyl group to a carboxylic acid and subsequent decarboxylation, is 1,3,5-trinitrobenzene (TNB). The work has focused on the degradation of TNB (which is generally regarded as nonreactive with hydroxyl radicals).

The first focus in evaluating the potential oxidation of TNB was to use a more aggressive reaction (i.e., a higher hydrogen peroxide concentration) similar to what has been used in soils to promote the oxidation of sorbed contaminants in soils.

The results of such moderately aggressive Fenton-like reactions (molar hydrogen peroxide/TNB ratios up to 400 catalyzed by $25 \mathrm{mM}$ ferrous sulfate) demonstrate that TNB was degraded by the Fentonlike reactions and that an equivalent of two nitro groups were displaced from the ring (and detected in the aqueous phase by ion chromatography). These results are anomalous to the molar stoichiometries reported for other water soluble aromatic compounds, which usually require only about 2-10 moles of hydrogen peroxide/mole of hydrocarbon degraded.

The first logical step in assessing the mechanism of degradation shown is to evaluate the participation of hydroxyl radicals. The same reactions mentioned above were repeated, but a hydroxyl radical scavenger was added. The results show that the same extent of TNB degradation occurred, even when hydroxyl radicals were scavenged from the system by excess isopropanol. These results suggest that another mechanism, other than hydroxyl radicals, was degrading the TNB.

To evaluate the potential for a reduction reaction, the reactions were repeated once more, but with the addition of the electron scavengers hydroxylamine or chloroform. The results indicate that the reactions did not occur with these electron scavengers present. The results confirm that TNB is being degraded by a Fenton-like reduction--a previously unreported phenomenon. Fenton's systems are highly oxidizing environments, and the presence of reducing reactions most likely provides an environment where both oxidations and reductions occur in concert.

The results provide a number of important ramifications for the treatment of nitroaromatic explosives. First, TNB, which has been considered an end-product of many degradation processes, can be degraded in an oxidizing/reducing Fenton's system. Secondly, the same hydrogen peroxide concentrations

that are necessary for degrading sorbed contaminants are effective in reducing TNB to products from which nitrate has been displaced. The results provide strong evidence that modified Fenton's reactions can 1) degrade sorbed nitroaromatic compounds in soils and sludges, and 2) degrade TNB with the potential for total mineralization of the ordnance compounds.

\title{
2.10. Gamma-Ray Spectrometry Utilization of NDE/NDA of Mixed Waste
}

\author{
Principal Investigator: R. L. Heath
}

The objective of this project was to establish the basis for extending the existing Gamma-ray Spectrum Catalogue program database to include data specifically related to the needs of the waste management community. Characterization of radioactivity in materials is a requirement in many phases of radioactive waste management. Movement, shipping, treatment, all activities which involve handling of mixed waste, or TRU categories of waste at all DOE sites will require that measurements and assessment documentation utilize basic nuclear data that are traceable to internationally accepted standard values. Major emphasis has been on the definition of data needs unique to the development and application of advanced measurement systems for radioactive waste characterization. 
The database incorporated in the original spectrum catalogues was assessed, comparing the database with the existing inventory of radionuclides in the DOE waste inventory. Leading experimental groups at major universities and DOE labs were consulted and involved as collaborators and/or participants in the beta review process for critique of the pilot of the CD-ROM edition of the Spectrum Catalogues. Interaction with the metrology research community involved in the development of advanced measurement systems for waste characterization was used to identify the major needs for new spectral data by the community. Identified needs included: (1) more detailed spectra for natural radioactive decay chains, (2) actinides, and (3) prompt gamma-ray spectra characteristic of thermal neutron capture and inelastic neutron scattering ( $n-n$ ') reactions for chemical elements. These data are needed to apply new techniques to a variety of measurement problems. This provided the basis for planning expanded Catalogue content and the development of measurement programs to generate new data for future editions of the Spectrum Catalogues.

This task provided the basis for determining the content of the first version of the new edition of the Catalogues in CD-ROM format, and the approach for offering information on the Internet through the Gamma-ray Spectrometry Center Web Site at the INEEL. It contributed to the development of the program plan for the new Gamma-ray Spectrum Catalogue Program funded by EM in late FY 1996. This new program incorporates a major scientific collaboration with Russian scientists who represent a significant resource for the generation of new spectral data for actinides and $\mathbf{n}-\mathbf{n}$ ' prompt gamma reaction spectra to be included in a specialized version of the Spectrum Catalogues under development for the waste characterization technology community.

\title{
2.11. Rapid and Ecologically-Relevant Risk Assessment of Mixed Contaminants in Groundwater
}

\author{
Principal Investigator: R. M. Lehman
}

The objective of this project was to field validate a microbial-based method and approach for assessing mixed contaminant bioavailability and toxicity in saturated subsurface systems. Contaminant risks are poorly quantified, and often conservatively estimated, resulting in high and unnecessary remediation costs. Treatment methodologies are being developed to remediate environments that may not pose potential risks, while ecologically-relevant endpoints are not being established to restore contaminated environments that may pose potential risks. Developing approaches and methods to rapidly and economically assess the actual risk posed by contaminants to humans and the environment would drastically lower overall remediation costs.

At INEEL's Test Area North, significant quantities of chlorinated solvents, radionuclides and sewage were injected via a waste injection well (TSF-05) into the Snake River Plain Aquifer-a major groundwater resource for southeast Idaho-resulting in a large contaminant plume. This highly transmissive aquifer exists in a thick sequence of basalt flows and thinner interbedded sediments. Because this contaminated fractured media in the subsurface ranks as one of the most intractable remediation issues, the plume at Test Area North represents an important class of sites and is an excellent candidate for conducting basic research related to contaminant distribution and remediation in environments where fractures dominate. Groundwater microbial communities in the vicinity of the contaminant plume were examined by Community-Level Physiological Profiling(es) - a rapid, multidimensional assay of community respiration of sole carbon sources. 
To determine the relationship between plume contaminants and community-level physiological profiles, defensible groundwater samples from saturated intervals at transition zones of differing permeability in the dissolved TCE plume at the Test Area North site, were collected in collaboration with other site investigators. Communities were compared by average metabolic response (to the tests) and multivariate comparison of their profiles. Community-Level Physiological Profiles were matrixed with collateral data on the concentrations of contaminants, major nutrients, and physical properties collected by other investigators to determine the true extent of environmental perturbation.

Community-Level Physiological Profiles were generated from Snake River Plain Aquifer groundwater from 27 wells inside and outside the TCE (prime contaminant) plume at concentrations of TCE up to $15,000 \mathrm{ppb}$. Principal components analyses of all the groundwater communities revealed a scattering of samples with the only reliable separation occurring between wells close to the injected site and wells unaffected by the contaminant plume. Because the 27 wells had been drilled for various purposes over the last $\mathbf{4 0}$ years they are not arrayed in an ordered transect or grid across the plume. Further, they differ in diameter, construction, depth of screened interval, and type of pump used to obtain samples. For this reason, principal components analysis, conducted on a set of three wells with similar construction etc., was used to evaluate differences in groundwater communities from "end member" locations with respect to TCE (Fig. 1). The three wells analyzed are injection well TSF-05, TAN-25 (a well 5 meters downgradient), and TAN-24A (a well downgradient past the southern end of the plume). Principal components analysis grouped independent replicate samples from the two contaminated wells closely, while discriminating the Community-Level Physiological Profiling from TAN-24A, the unaffected location. Factors 1 and 2 captured $35.0 \%$ and $16.2 \%$ of the total variance in the data set, respectively. Main effects of wells sampled on Factor 1 scores were determined from Community-Level Physiological Profiling between the downgradient TAN-24A communities and either TSF-05 or TAN-25. No significant difference was seen between wells TSF-05 and TAN-25 ( $p=0.194)$. Amino and carboxylic acids were preferentially utilized by groundwater communities from locations with high TCE concentrations while carbohydrates were utilized to a greater extent by communities from uncontaminated sites. 


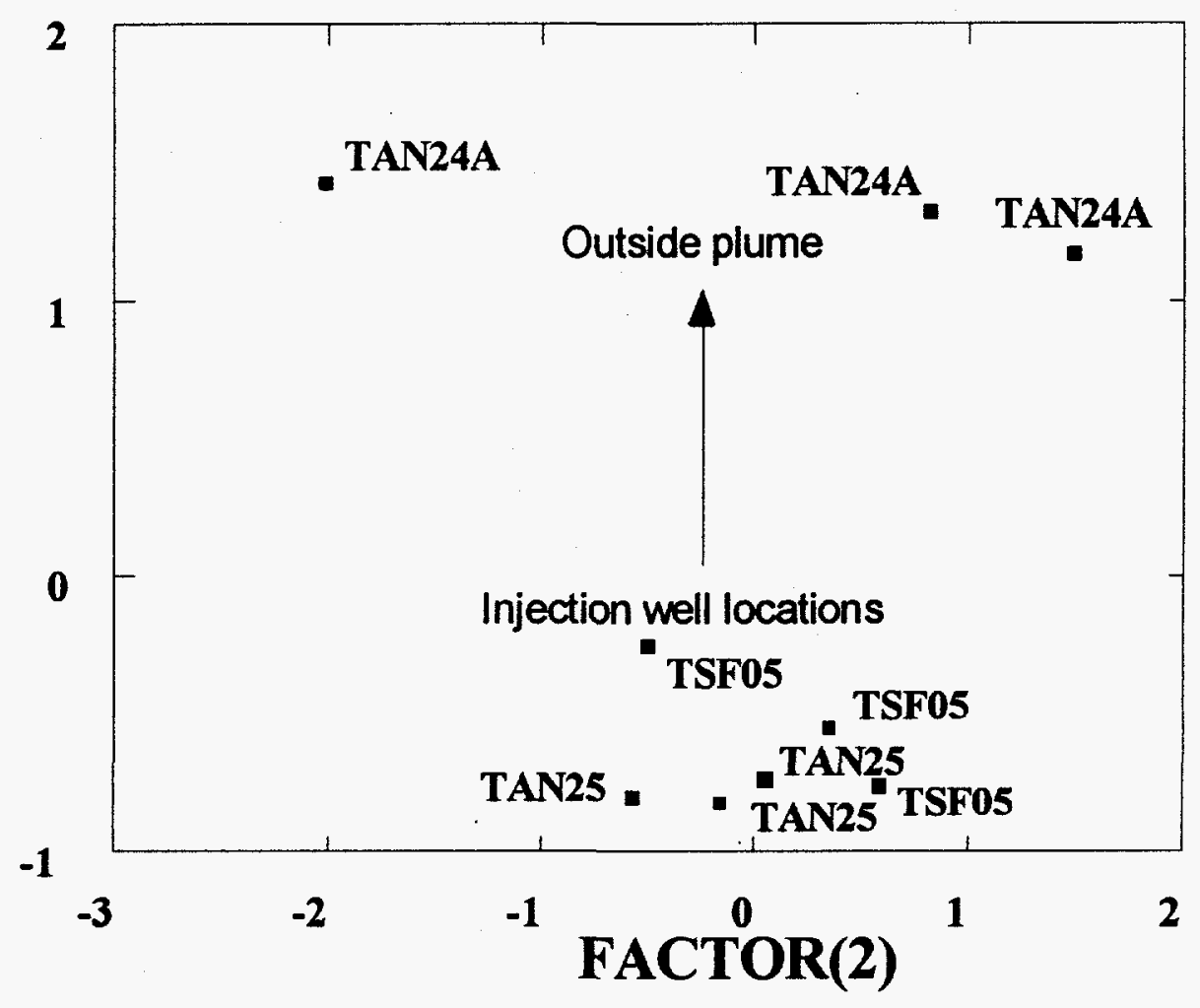

Figure 1. PCA on TAN groundwater communities. TSF-05 is injection well; TAN-25 is proximal to injection wells; TAN-24A is outside TCE plume. Arrow indicates potential recovery path

Figure 1. Lacations of injection/test wells and plume.

Additional samples must be collected to achieve statistically-significant results under heterogeneous field conditions and to discriminate more subtle effects of the contaminant plume versus those due to natural environmental factors.

Determining the feasibility of using spatial gradients in plume concentrations, and the impact for modeling temporal recovery of the subsurface ecosystem following treatment, was not possible because of regulatory issues that limited the number of samples that could be obtained. Now that these issues are resolved, opportunities for further sample analysis to complete original project objectives are underway using incremental funding from several sources.

An abstract summarizing current finding was accepted for presentation at the 4th International Symposium on In Situ and On-Site Bioremediation sponsored by Battelle in May, 1997.

As a follow-on activity, field validation for exploration of the Community-Level Physiological Profiling approach for ecological risk assessment in terrestrial systems has received some discretionary lab funding due to the increased opportunity for defining restoration endpoints in terrestrial (verses aquatic and groundwater) systems. 


\title{
2.12. Technology Demonstration of $\mathrm{Cr}(\mathrm{VI})$ Reducing Bioreactor
}

\author{
Principal Investigator: C. E. Turick
}

The objective of this project was to field test a bioreactor designed for $\mathrm{Cr}(\mathrm{VI})$ reduction of contaminated groundwater.

This project proceeded with cooperation (detailed below) from the following companies:

Environmental Research and Development, Inc., DuPont, National Chromium, and Environmental Risk

Limited. In addition, officials at the Tobyhanna Military Base, Tobyhanna, Pennsylvania granted permission for the use of their facilities for a portion of this project. Environmental Research and Development Inc. also offered technical and logistic support as well as consultation throughout this project.

The packed-bed bioreactor consists of $990 \mathrm{~mL}$ of solid supports (BIO-SEPTM beads) and a liquid volume of $550 \mathrm{~mL}$. Bacteria, enriched from $\mathrm{Cr}(\mathrm{VI})$ contaminated soil, were immobilized into the beads in order to increase bacterial density, thereby increasing reactor volumetric productivity. BIO-SEPTM Beads are a polyarimid-powdered activated carbon composite that provides a porous matrix of bacteria containment. Beads and frequent technical and economic consultation were provided by DuPont. Neither $\mathrm{Cr}$ adsorption onto the beads nor abiotic $\mathrm{Cr}(\mathrm{VI})$ reduction occurred during bioreactor operations.

$\mathrm{Cr}(\mathrm{VI})$ reduction in this bioreactor resulted in $\mathrm{Cr}$ (III) without the need to add other inorganic chemicals as reductants, or for $\mathrm{pH}$ adjustment. This resultant, less mobile, benign $\mathrm{Cr}$ (III) may not need to be removed during groundwater remediation activities but simply reinjected to sorb onto soil particles in the subsurface and thereby become immobilized. Current reasons for removing $\mathrm{Cr}$ (III) from treated groundwater includes the presence of the other chemicals present in the water after treatment. The allowance for reinjection of CR(III) from bioreactor effluent is a decision for regulators. Lately, regulators are taking a more liberal view of $\mathrm{CR}$ (III), especially if $\mathrm{Cr}$ (III) is in low concentration.

Bioreactors can contribute considerable organic matter to the effluent, in the form of bacteria that exist in the system. The solid supports used in this study entrapped the bacteria in a very low biomass output, thereby decreasing the chemical oxygen demand of the effluent.

This technology may be used alone and replace existing less efficient technologies, or in conjunction with conventional methods as a pretreatment step for treatment of surges of $\mathrm{Cr}(\mathrm{VI})$, or as a post treatment polishing step.

In summary these successful trails of a $\mathrm{Cr}(\mathrm{VI})$ reducing bioreactor provides the following results:

- Industrial effluents and groundwater were successfully treated with this bioreactor

- An inexpensive feedstock was identified for bacterial reduction of Cr(VI)

- The bioreactor operated successfully in the range of 200 to $120 \mathrm{ppm} \mathrm{Cr(VI)}$

- The bioreactor operated successfully in the $\mathrm{pH}$ range of $4.3-7.1$

- $\quad \mathrm{pH}$ was increased during $\mathrm{Cr}(\mathrm{VI})$ reduction in the bioreactor 
- Nitrate did not inhibit bioreactor performance

- The need for chemical additives was reduced by as much as $90 \%$

- The bioreactor produced minimal biomass output.

Follow-on activities: Scale-up and operation of a bioreactor for $\mathrm{Cr}(\mathrm{VI})$ reduction. At the present time the INEEL is working with DuPont to determine capital costs of a full scale reactor as well as determination of a potential staging facility. ERAD is also pursuing support in using this technology for clean-up of chromate contamination from chromite ore tailings. A preliminary market analysis has demonstrated considerable potential for the area of $\mathrm{Cr}(\mathrm{VI})$ conversion. TTV is currently performing a thorough marked analysis on this topic.

\subsection{Box Canyon Polyurethane Research}

\section{Principal Investigators: S. L. Barrie and K. J. Dooley}

The objective of this project was to demonstrate the use of several backfill materials that can be hydrophilic and hydrophobic, and/or rigid or elastic in order to effectively install vadose zone instrumentation.

Monitoring the vadose zone for water and contaminant migration requires several instruments to be installed in a single borehole. Installing several instruments with electrical leads and access tubes brought to land surface creates the potential for rapid movement of water in the borehole itself along gaps and conduits in the backfill material. Thus, there exists a growing need to evaluate newer backfill materials that include epoxies and foams that can be hydrophilic or hydrophobic, and/or rigid or elastic.

The backfill material required for installing vadose zone instruments would bond to basalt, set rapidly enough that fracture permeation would be minimal, be non-sorbing with respect to water or contaminates, and be economical to emplace. A family of materials that meet these requirements has been identified and is available commercially 
The materials to test are from Strata Tech, Friendswood, Texas, and include the following:

\section{Material}

$\begin{array}{llll}\text { ST-540 } & \text { Elastic } & \text { Hydrophilic } & \text { Minimal Sorption } \\ \text { ST-545 } & \text { Rigid } & \text { Hydrophilic } & \text { Minimal Sorption } \\ \text { ST-504 } & \text { Elastic Foam } & \text { Hydrophilic } & \text { Imbibes Water } \\ \text { ST-541 } & \text { Rigid Foam } & \text { Hydrophilic } & \text { Minimal Sorption }\end{array}$

All materials are injected into the well bore using commercially available pumps and tubing. The primary function of any sealing material is to isolate instruments in a borehole set in fractured basalt and yet not interfere with water and contaminate migration. Currently bentonite and Portland cement are used to isolate intervals of boreholes, although their ability for doing this is being continually evaluated throughout the world.

The following lab tests were done and the visual results evaluated using epoxies and foams:

- seal to rock and soil

- $\quad$ seal to wetted rock and soil

- cannot react with electrical insulation or access tubing

- cannot significantly permeate sands used around tensiometers and lysimeters

- cannot fill adjacent fractures

ST-540 and ST-545 were found to be excellent sealants, permeated sand to depths of 1 to 2 inches before setting in their final state, and cost $\$ 3$ to $\$ 5$ per gallon. However, considerable skill is required for accurate placement due to their short setting time coupled with the length of time needed for the materials to be pumped to the depth required in a borehole. These problems were not fully resolved on our schedule.

ST-504 was found to shrink when exposed to drying which could cause voids to develop along the borehole and potential loss of seal; but, the installed cost was 5 to $10 \%$ that of ST-540 and ST-545, and it was easy to install, since the McCabe Bros. had considerable experience installing it in engineering structures. The shrinkage effects were not studied further due to schedule requirements

ST-541 was comparable in cost to ST-540, ST-545, and ST-504 but was found to expand approximately 23 times its liquid volume. This expansion greatly reduced the final cost of sealing a borehole to approximately that of the conventional bentonite and sand backfill materials used to seal boreholes. ST-541 was selected for further evaluation at the Box Canyon Site. 
The material required at Box Canyon needed several properties. The first property was the ability to inflate low cost packers and force instruments into firm contact with the borehole wall. A shop test was conducted by inflating packers against clear PVC pipe and the ST-541 material performed well. It was found during this test that excess material needed to be injected so that the foam would expand under partially confined conditions and fully pressurize the packers. Based on this evaluation and further installation tests an expansion factor of 20 was used for the foam.

The expansion factor was rechecked while installing instruments at Box Canyon by monitoring the final state of injected ST-541. Typically the computed volumes were found to fill the boreholes above land surface. Also several opportunities occurred where the upper packer could be observed while the foam expanded to its final volume. The foam appeared to have sealed the boreholes well and to have filled the packers to the required volume.

Note that the number of instruments placed in each borehole would have been greatly reduced if conventional borehole backfilling methods had been used. Also the time domain reflectrometer wave guides could not have been deployed with conventional materials and methods. With out the expansion provided by the foam the TDR wave guides could not have been placed firmly against the borehole wall.

Further work is needed to improve the speed of foam installation and increase the density of instruments installed. The foam grouting technology is a viable candidate to proceed with. Another potential foam grouting application is to seal large areas for waste isolation. The grouts could be injected in buried waste, or if fracture systems could be located in the underlying bedrock, the fractures themselves could be sealed against vertical migration of contaminants.

\title{
2.14. Comparison of Ion Mobility Spectrometry Screening with Method 8330
}

\author{
Principal Investigator: A. B. Crockett
}

The objective of this effort is to quantitatively evaluate a solvent extraction/Ion Mobility Spectrometry (IMS) field screening procedure as a potentially cheaper, faster and more accurate method of screening soils for high explosive residues.

Soils contaminated with explosives constitute a high priority problem at some Department of Energy facilities and many Army installations. Because explosives in soil are often heterogeneously distributed and require high-density sampling, field screening is essential to characterize sites more quickly, economically, and accurately. Current immunoassay and colorimetric field screening procedures have proven useful, but have significant per sample costs and limited throughput. Often, only a single analyte or analyte group determination is possible per sample. At present, several field screening procedures are available for TNT in soil, three procedures for RDX and one procedure for 2,4-DNT and ammonium picrate/picric acid (AP/PA). Ion mobility spectrometry has been used for several years in law enforcement work to detect explosives in air at ppt levels, but limited work has been done to apply the technique to quantifying explosives in soils. IMS offers great potential since many compounds (TNT, RDX, PETN, DNT, TNB, NG, etc.) can be quantified simultaneously in an acetone extract within a few seconds and at a cost of under a dollar per sample. This study involved the comparison of IMS screening with EPA's standard method for explosives, Method 8330. The U.S. Army Cold Regions Research and Engineering Laboratory (CRREL) provided a large number of soil samples that had been collected from three locations at each of three explosive contaminated installations. The samples had been dried, ground, homogenized, 
and analyzed in duplicate by Method 8330. Duplicate two gram aliquots of these samples were extracted with $10 \mathrm{~mL}$ of acetone by shaking for three minutes, allowed to settle, then analyzed by IMS for Method 8330 compounds. Half of the extracts from one location have also been analyzed in duplicate by IMS for TNT. Results from TNT contaminated soils look good. Based on these results, the intention is to further develop and evaluate IMS for simultaneously quantifying multiple analytes. The ultimate objective is to provide adequate validation data to EPA for inclusion of the method as a screening procedure in SW-846. For field application, the extraction procedure should be changed to extract $20 \mathrm{~g}$ of moist soil with $100 \mathrm{~mL}$ of acetone.

A study was conducted by Jenkins et al. (1996) to assess the extent of short-range heterogeneity present in contaminant concentrations for surface soils at explosives contaminated sites. Intensive sampling was conducted over short distances. Discrete and composite samples were analyzed by both colorimetric field screening techniques (EnSys) and standard laboratory protocols (EPA Method 8330). Three locations were sampled at each of three installations, duplicate samples were analyzed by each method, and the results used to estimate the relative contributions of analytical error and sampling error to the total uncertainty associated with sample collection and analysis for explosives residues. The major contaminant at seven of the nine sampling locations was TNT, and the colorimetric field screening method provided results that were in excellent agreement with laboratory results using SW846 Method 8330 (Jenkins et al. 1996).

Samples from this study were archived and subsequently made available by CRREL and the U.S. Army Environmental Center for use in evaluating IMS as a field screening technique for explosives in soil. IMS holds considerable potential as a screening method since the instrument can simultaneously detect multiple compounds in acetone extracts of soil. IMS has long been used for forensic purposes to detect extremely low levels of explosives and chemical warfare agents in air. Relatively little work has been done to quantify explosives in soil and we know of no published reports comparing IMS screening results with EPA Method 8330 (Avolio et al. 1995, Rodacy and Leslie 1992)

The objective of this study has been to evaluate the utility of IMS as a screening technique for quantifying explosive residues in soils.

The instrument used for this work has been a PCP 110 equipped with an injection port. While this instrument can be transported to the field, it is not hand portable and the current software is inadequate for simultaneous real time quantification of multiple explosives. The $2 \mathrm{~g}$ soil samples were extracted in batches of 5 to 6 by shaking with $10 \mathrm{~mL}$ of laboratory grade acetone.

CRREL provided duplicate homogenized $2 \mathrm{~g}$ soil samples from the sites they had previously characterized. The initial effort was to develop a calibration curve for TNT and analyze a composite sample from each of the nine locations sampled by Jenkins. The effort verified that the IMS could instantaneously detect the presence of TNT, DNT and TNB in the samples. Efforts aimed at developing a linear calibration curve demonstrated that injecting varied volumes of a standard resulted in deviations from linear behavior in calibration. Apparently, larger volumes of acetone complicates the ion chemistry which is reflected in the response to the explosive compound of interest. A chloride ion generator was added to the system to stabilize the reactant ions. Typically chloride-reactant-ion-chemistry is used to increase sensitivity to nitroaromatics. In this application, sensitivity of the IMS is not an issue and the chloride was used mainly to stabilize the reactant ion peak behavior, and to hopefully suppress the effect of acetone on explosive response over varying injection volume sizes. The temporary solution to the problem has been to use a consistent injection volume, in our case, 2 L. Some IMS systems rely on pre-evaporation of the solvent before sample introduction into the IMS. Direct solution injection was used in this case to increase 
throughput, reduce cross contamination potential, and simplify the methodology. Good calibration curves were developed using the constant volume injection method for 3 to 5 different standards. It became apparent during the investigation that high levels of non-target explosives present in the same samples can detrimentally effect the response to a target explosive. This interference effect can be attributed to ion chemistry complications, such as competition for charge among analytes.

To simplify the problem, we picked a set of eight samples (in duplicate) containing a wide range of TNT and generally free of potentially interfering other explosives (Location 1). Samples were then diluted as needed for analysis. After an initial run, the samples were all rerun using improved procedures and dilution estimates from the first run. The time consuming portion of the analysis procedure was making the sample dilutions which ranged from $1111: 1$ to 500,000:1. IMS analysis was a quick step with the 15 point calibration curve and triplicate injections of all 16 samples being completed in 1.5 hours.

IMS and Method 8330 data were compared using linear regression. Ideally the regression line relating screening, and 8330 data should have an intercept to 0 and a slope of 1 . For the IMS data, the slope was 0.99 and the intercept was -351 . For comparison, EnSys colorimetric screening data as run by Jenkins et al. (1996) was also compared to Method 8330 data. For EnSys, the slope was 0.78 with an intercept of 833. While the IMS model is closer to the ideal, the spread of data is greater than with EnSys. The correlation coefficient for IMS was 0.84 and for EnSys was 0.96 .

These results demonstrate that IMS can be used to rapidly quantify TNT in soil samples free of other explosives and presumably could be effectively used to look at many other individual compounds just as effectively. IMS can also be used to easily detect the presence of a variety of explosives (excluding HMX) but we have yet to demonstrate the capability of simultaneously quantifying multiple explosives. This should be possible with improved software, installation of a short chromatographic column or a programmed injection/desorption front end to separate compounds. If this problem can be overcome, IMS should develop as a rapid site characterization tool for quantifying multiple individual compounds at low per sample cost. The main limitation of the technique would be instrument cost and operator training. We intend to continue laboratory development and evaluation of the technique and if these results are positive, conduct field evaluations as well.

\section{References}

Avolio, J., R. DeBono, and P. Radwanski, 1995, Ion mobility spectrometry (IMS) field screening methods and analysis of explosives in contaminated soils. In: Field Screening Methods for Hazardous Wastes and Toxic Chemicals, VIP-47, Air \& Waste Management Assoc., Pittsburgh, PA, 2:1037, abstract only.

Jenkins, T.F., C.L. Grant, G.S. Brar, P.G. Thorne, and T.A. Ranney, 1996, Assessment of Sampling Error Associated with Collection and Analysis of Soil Samples at Explosive Contaminated Sites (Phase 1): Status Report, Special Report 96-15, U.S. Army Corps of Engineers, Cold Regions Research and Engineering Laboratory.

Rodacy, P. and P. Leslie, 1992, Ion Mobility Spectroscopy as a Means of Detecting Explosives in Soil Samples, Sand-92-1522C, Sandia National Laboratories, Albuquerque, NM, 7 pp. 


\title{
2.15. Natural Attenuation of Groundwater at Test Area North
}

\author{
Principal Investigator: D. T. Maiers
}

The objectives of this effort were to provide a science-based indication of whether Natural Attenuation and biodegradation could be occurring at sites with conditions such as those found at Test Area North at the INEEL.

To accomplish this project's objectives, several tasks were undertaken. The first task was to collect groundwater samples from throughout the Test Area North area (including both TCE-contaminated and uncontaminated regions) and determine the presence or absence, and relative abundance of microbial populations typically involved in in situ aerobic TCE destruction. These microbial populations were then assessed with regard to their ability to destroy TCE in laboratory flask studies using actual contaminated groundwater from Test Area North. The final task associated with this project was to provide the laboratory data to EM-40 for use in determining the efficacy of proceeding with detailed studies designed to quantify and qualify the Natural Attenuation and biodegradation occurring at Test Area North.

Microbial populations typically involved in aerobic degradation of TCE (methanotrophs, propanotrophs, and phenol-oxidizing pseudomonads) were found in all Test Area North contaminated groundwater samples. Their relative abundance was estimated by the Most Probable Number technique. and determined to be adequate to potentially impact TCE destruction at this site. When these microbial populations were then evaluated for their ability to degrade TCE in actual Test Area North groundwater, it was determined that up to $50 \%$ of the TCE present (about $200 \mathrm{ppm}$ initially) could be aerobically degraded within a six week incubation period. This type of degradation capability by indigenous organisms provides a strong line of evidence for the potential for Natural Attenuation. The data from these studies was provided to EM-40 who subsequently provided it as information to DOE, EPA, and the State of Idaho. It appears likely at this time that an agreement to pursue bioremediation and Natural Attenuation for the Test Area North site may be reached, potentially saving a great deal of funding on the site remediation. In addition, this project was largely responsible for opening the gate to a large number of other research and development projects that are leveraging sampling costs and data sharing to maximize the research value. 


\section{FUNDING}

\subsection{Overall Project}

FY-96 budget: $\$ 677 \mathrm{~K}$

Total spent: $\$ 672 \mathrm{~K}$

\subsection{Individual Projects}

1. Volume source efficiencies and coincidence corrections

$\$ 60 \mathrm{~K}$ budget

$\$ 60 \mathrm{~K}$ spent

2. Innovative waste stabilization project

$\$ 63 \mathrm{~K}$ budget

$\$ 55 \mathrm{~K}$ spent

3. Application of electrochemical oxidation and cross-flow microfiltration for VOC, strontium, and cesium removal from groundwater at Test Area North

$\$ 47 \mathrm{~K}$ budget

$\$ 47 \mathrm{~K}$ spent

4. Low cost vitrification alternative

$\$ 50 \mathrm{~K}$ budget

$\$ 50 \mathrm{~K}$ spent

5. Removal of radionuclides from Test Area North injection well water

$\$ 50 \mathrm{~K}$ budget

\$48K spent

6. Passive soil vapor extraction

$\$ 50 \mathrm{~K}$ budget

$\$ 51 \mathrm{~K}$ spent

7. Rapid geophysical surveyor for unexploded ordinance

$\$ 10 \mathrm{~K}$ budget

$\$ 6 \mathrm{~K}$ spent

8. In situ sampling of aqueous-phase contamination of chlorinated solvents

$\$ 85 \mathrm{~K}$ budget

\$76K spent 
9. Evaluation of Fenton's based remediation for INEEL explosive contaminated soil \$14K budget

\$13K spent

10. Gamma-ray spectrometry utilization of NDE/NDA of mixed waste $\$ 20 \mathrm{~K}$ budget

$\$ 18 \mathrm{~K}$ spent

11. Rapid and ecologically relevant risk assessment of mixed contaminants in groundwater $\$ 42 \mathrm{~K}$ budget

$\$ 44 \mathrm{~K}$ spent

12. Technology demonstration of $\mathrm{Cr}$ (VI) reducing bioreactor

$\$ 49 \mathrm{~K}$ budget

\$47K spent

13. Box Canyon polyurethane research

$\$ 20 \mathrm{~K}$ budget

\$26K spent

14. Comparison of ion mobility spectrometry screening with Method 8330

\$5K budget

\$5K spent

15. Natural Attenuation of groundwater at Test Area North

$\$ 112 \mathrm{~K}$ budget

$\$ 113 \mathrm{~K}$ spent 


\section{RESULTS}

Of the FY-96 projects funded with Proof-of-Concept funds, most of the 15 resulted in successful demonstration of a concept or technology. Following are the projects results:

1. Volume Source Efficiencies and Coincidence Corrections: This project developed a methodology for modeling Germanium $(\mathrm{Ge})$ detector efficiencies by Monte Carlo techniques, and for the automatic calculation of coincidence summing corrections for extended sources. These techniques can be applied to the assay of samples and in situ, gamma-ray Ge measurements. The PIs are working with a private sector partner to commercialize the technology.

2. INEEL Stabilization Project: This project utilized three solidification materials (phosphate, iron sulfate, and hydroceramics) to stabilize incineration ash and shredded cryogenic waste. All of the waste-form materials functioned successfully as waste containment materials. Mixed Waste Focus Area Programmatic and Quick-win funding has been obtained for application of the phosphate material.

3. Application of Electrochemical Oxidation and Cross-Flow Microfiltration: This project applied electrochemical oxidation and cross-flow microfiltration for treatment of groundwater at Test Area North to destroy the trichloroethylene and remove cesium and strontium. Electrochemical oxidation removed the trichloroethylene to below the detection limit for chemical oxygen demand (low range). The removal of strontium by crossflow microfiltration was evaluated using fluoride, phosphate, and carbonate precipitating agents. Phosphate was most effective at the low concentrations resulting in $83 \%$ removal. This technology, which is available through a commercial vendor, is ready for pilot scale demosntration.

4. Low Cost Vitrification Alternative: This project stabilized incinerator ash in a ceramic waste form using a liquid-phase sintering technology. The project demonstrated the merits of this RocTec ${ }^{T M}$ technology for processing five different surrogates for hazardous and radioactive compounds as a function of waste loading (up to $80 \mathrm{vol} . \%$ ) and ash from a municipal waste incinerator. It was demonstrated that these wastes can be fabricated into sintered pellets consisting of a vitreous/crystalline form without requiring a melter. This technology, which is available from a commercial vendor, received MWFA Quick-Win funding in FY-97.

5. Removal of Radionuclides from TRA Groundwater: This project utilized ion exchange sorbents to remove ${ }^{90} \mathrm{Sr}$ and $/$ or ${ }^{137} \mathrm{Cs}$ from groundwater. The groundwater treatability studies indicate that there are a number of sorbents available that effectively remove cesium and strontium from groundwater. As a result of this project, the PI has received follow-on programmatic funding to pursue applications on the ICPP perched grounwater. 
6. Passive Soil Vapor Extraction: Successful demonstration of this technology at the Boise airport has resulted in requests for its installation at other sites. Most recently an installation has been requested at a gasoline station in Preston Idaho.

7. Rapid Geophysical Surveyor for Unexploded Ordinance: This project mapped the distribution of surface and buried unexploded ordnance (UXO) using magnetic field mapping equipment. The Rapid Geophysical Surveyor (RGS), originally developed at the INEEL and licensed to Sage Earth Science, produced, at two sites, high fidelity magnetic field maps that show the distribution of ferrous and magnetic debris. This technology is available through Sage Earth Science.

8. In Situ Sampling of Aqueous-Phase Contaminants by Chlorinated Solvents: This project improved the design of the in situ sampler, developed in FY-95, for sampling methane in addition to trichloroethene (TCE), generating calibration curves for methane, and improving the detection limits. A detection limit of $2 \mathrm{ppb}$-wt for TCE was obtained in the laboratory using a gas chromatograph (GC) for the sample analysis, and a detection limit of $10 \mathrm{ppb}$ wt was obtained when the samples were analyzed in the field. At patent of this process is being pursued.

9. Evaluation of Fenton's Based Remediation for INEEL Explosive Contaminated Soil: This project evaluated using modified Fenton's reactions for remediation of soil contaminated with explosives. A very high degree of TNT destruction occurred in aqueous solutions in short time frames. In addition, conditions were found to bypass the TNB endpoint barrier in the destruction pathway.

10. Rapid and Ecologically Relevant Assessment of Mixed Contaminants in Groundwater: Due to troubles obtaining approval for sample collection, this project was not able to achieve the outcome hoped for. Additional Laboratory Directed Research and Development funds have been obtained the pursue the concept further.

11. Gamma-Ray Spectrometry Utilization for DEE/NDA of Mixed Waste: This project produced a specialized data collection in CD-ROM format that contains radionuclide decay data, gamma-ray spectra, and alpha particle spectra for radionuclides of interest in characterization and assay of TRU and mixed waste materials at INEEL. This task provided the basis for the determination of the content for the first version of the new edition of the Catalogues in CD-ROM format and the approach for offering information on the Internet through the Gamma-ray Spectrometry Center Web Site at the INEEL. This project has received follow-on programmatic funding. 
12. Technology Demonstration of Cr(VI) Reducing Bioreactor: This project demonstrated a reactor for the biochemical reduction of toxic and soluble hexavalent chromium ( $\mathrm{Cr}[\mathrm{VI}])$ to the less soluble and benign trivalent chromium ( $\mathrm{Cr}[\mathrm{III}])$. The reactor successfully demonstrated using drag-out bath effluent from a military chromium plating facility and chromium contaminated groundwater from an aquifer in northeastern Connecticut. $\mathrm{Cr}(\mathrm{VI})$ reduction in this bioreactor resulted in $\mathrm{Cr}$ (III) without the need to add other inorganic chemicals as reductants or for $\mathrm{pH}$ adjustment. This project has received programmatic follow-on funding.

13. Box Canyon Polyurethane Research: This project injected polyurethane in vadose zone monitoring wells to isolate instruments. Strata Tech, Friendswood, Texas, materials ST-540 and ST-545 were found to permeate sand to depths of 1 to 2 inches before setting in their final state. The materials were found to be excellent sealants and cost $\$ 3$ to $\$ 5$ per gallon.

14. Comparison of IMS Screening with Method 8330: This project quantitatively evaluated a solvent extraction/Ion Mobility Spectrometry (IMS) screening procedure for a cheaper, faster, and more accurate method of screening soils for high explosive residues. IMS was found to compare favorably to other field methodology and method 8330 for filed screening of explosives contaminated soils. In addition, the costs and time associated with screening by IMS is much less than that of other field techniques (for comparable data). Thisproject has received follow-on funding through Laboratory Directed Research and Development funds.

15. Natural Attenuation of Groundwater at Test Area North: This project provided a science-based indication of whether Natural Attenuation could be occurring at sites with conditions such as those found at Test Area North at the INEEL. Microbial populations typically involved in aerobic degradation of TCE (methanotrophs, propanotrophs) abundance was estimated by the Most Probable Number technique and determined to be adequate to potentially impact TCE destruction at Test Area North. When these microbial populations were then evaluated for their ability to degrade TCE in actual Test Area North groundwater, it was determined that up to $50 \%$ of the TCE present (about $200 \mathrm{ppm}$ initially) could be aerobically degraded within a six-week incubation period. Several sources of follow-on funding have been obtained to further the results of this effort. 